Bol. Acad. peru. leng. 66. 2019 (83-111)

\title{
PRÉSTAMOS LINGÜÍSTICOS EN EL QUECHUA ACTUAL DE LAS COMUNIDADES DEL DISTRITO DE PACCARECTAMBO
}

\section{LINGUISTIC LOANS IN THE CURRENT QUECHUA OF THE COMMUNITIES OF THE PACCARECTAMBO DISTRICT}

\author{
Niel Palomino Gonzales \\ Universidad Andina del Cusco
}

\section{Resumen:}

La investigación expone y analiza los principales préstamos lingüísticos que los quechuahablantes nativos del distrito de Paccarectambo emplearon durante los primeros meses del año 2016 en su interacción cotidiana. La metodología empleada es la siguiente: se han grabado las conversaciones de quechuahablantes monolingües de 50 años a más en sus distintas facetas cotidianas. Luego, se procedió con la transcripción de los audios. Con los textos transcritos, se constituyó el CORQUERUPA (Corpus del Quechua Rural de Paccarectambo). Este corpus fue sometido a un análisis bajo los criterios léxicosemánticos, etimológicos, fonológicos y morfológicos. Los resultados obtenidos evidencian que en las comunidades campesinas de Paccarectambo el quechua está repleto de préstamos lingüísticos, diacrónicamente provenientes del latín y carentes de equivalencias en el quechua. Dichos préstamos, al ser adoptados por el quechua, han sufrido una adaptación morfofonológica. Los extranjerismos en el quechua actual son indirectos y pertenecen más a la categoría sustantivo. 
Con todo esto, se propone el préstamo lingüístico como una posibilidad para revitalizar el quechua y hacer de este una lengua de estos tiempos, con términos que puedan expresar conceptos científicos diversos.

\section{Abstract:}

The research exposes and analyzes the main loanwords that native Quechua speakers from Paccarectambo district in Paruro province, Cuzco used during the first months of 2016 in their daily interaction. For this study, the conversations of the Quechua speaking farmers have been recorded in their different communicative situations like working the farm, resting, grazing cattle or traveling. Once the recording was finished, we proceeded with the transcription of audios. The age of Quechua-speaking farmers ranges about 50 to more years. With the transcribed texts, we built the CORQUERUPA abbreviation, (Paccarectambo Rural Quechua Corpus). This corpus was subjected to an analysis, mainly under the semantic, phonological and morphological lexical criteria. At the end, the results obtained show that in rural communities of Paccarectambo the Quechua language is full of loanwords mostly direct or indirectly from Spanish. One result also shows that the greatest number of loanwords belong to noun grammatical category. In addition, most of the loanwords have no equivalent in Quechua. On the other hand, the loanwords come from Latin that are adopted by the Quechua have undergone a morpho phonological adaptation that is the foreign words have adapted to the phonological and morphological Quechua system. Currently foreign words in Quechua are indirect and belong more to the noun category. Finally, the loan mechanism is proposed as a possibility to revitalize Quechua and make it a modern language with terms that can express diverse scientific concepts with precision and according to the characteristics of scientific language.

Palabras clave: diacronía; extranjerismo; préstamo lingüístico; quechua.

Key words: adaptation; diachronic; foreign expression; loan words; quechua; Quechua speakers; and synchrony. 
Fecha de recepción: $\quad$ 10/09/2019

Fecha de aceptación: $\quad 30 / 11 / 2019$

\section{Introducción}

En Lingüística, préstamo alude a la adopción de palabras que los hablantes de una lengua hacen de la otra. Este fenómeno ha despertado bastante interés en los más descollantes lingüistas del mundo desde los más antiguos hasta los más actuales. Asimismo, su conveniencia o no ha generado un ardiente debate entre sus defensores y sus detractores, que terminó, felizmente, en un consenso a favor del inevitable préstamo. En el Cuzco, los préstamos que el quechuahablante nativo ha hecho de las otras lenguas son muy evidentes. Y no podría ser de otra manera, porque el préstamo es un fenómeno propio de toda lengua viva. Sin embargo, en el Cuzco también los préstamos lingüísticos al quechua tienen más que detractores, iracundos enemigos obstinados en «evitar» a capa y espada estos préstamos. Los detractores son la mayoría de los integrantes de la Academia Mayor de la Lengua Quechua. Ellos, autonombrándose lingüistas, se perciben como dueños del quechua. Por ejemplo, ellos muestran una actitud hiperpurista absurda al rechazar a ultranza estos préstamos de manera apasionada y fanática; esto es, sin fundamentación científica y lingüística. Y en lugar de los préstamos lingüísticos, los «académicos» «crean» curiosos e hilarantes términos equivalentes como los siguientes: amp'ara 'mesa', qilqamayt'u 'libro', simi fhafmi 'sílaba', uyarina rimanapaqway 'celular', qilqana ‘'lápiz, lapicero, plumón?’, etc. En su defecto, la otra modalidad a la cual recurren es que intentan resucitar arcaísmos como kaka 'tío', mulla 'sobrina', maq'aqe 'padrino'.

Los supuestos neologismos, creados no por el pueblo, que lo haría de manera natural, sino, por los académicos, que lo hacen de manera forzada, no tienen aceptación ni acogida de parte de la gran cantidad de quechuahablantes. Así, estos hablantes o usuarios reales no emplean en su interacción cotidiana, «neologismos», e incluso «arcaísmos». El 
resultado final de esta locura de «inventar» nuevas palabras o revivir arcaísmos es el aislamiento y la extinción del quechua cuzqueño del proceso de estandarización del quechua tawantinsuyano.

Empero, indiferentes a los académicos, los dueños verdaderos de la lengua, es decir, los quechuahablantes, no han dudado en adoptar y adaptar vocablos de otras lenguas, logrando con ello enriquecer y mantener vivo el quechua durante más de cinco siglos.

En los tantos congresos académicos «mundiales» que convocan solo los miembros de la Academia Mayor de la Lengua Quechua, que como se sabe son pentavocalistas, nunca han tratado científicamente el fenómeno del préstamo. Ven este recurso, sin razón, como un peligro que atenta contra la "pureza» del quechua. Y, en lugar de actualizarse y optar por el préstamo de manera cuidadosa como lo hace la población usuaria, lo que han hecho es oponerse de manera fanática y radical.

Viendo a la luz de la ciencia lingüística, estas actitudes arriba descritas, han estancado la vitalidad del quechua y han impedido que se modernice con los préstamos como lo hace toda lengua con vigor y vigencia.

En tal sentido, el objetivo de esta investigación es exponer y analizar los principales préstamos lingüísticos que usan los quechuahablantes nativos del distrito de Paccarectambo, de la provincia de Paruro, del departamento del Cuzco, en su interacción cotidiana. Es decir, cómo es el proceso de adaptación morfofonológica de los préstamos; qué tipo de categoría es el más predominante en los préstamos; si los préstamos son directos o indirectos; en qué proceso de nativización están dichos préstamos y, finalmente, cuáles son las ventajas de los préstamos para la lengua. Es decir, saber si los préstamos son amenaza o beneficio para el quechua.

Así pues, el siguiente artículo está sistematizado de la siguiente manera: se presentan la introducción, el marco teórico, el método y los materiales, los resultados, la discusión de estos y las conclusiones. 
https://doi.org/10.46744/bapl.201902.004

\section{Contacto de lenguas y cambios lingüísticos}

Se denomina contacto de lenguas a un fenómeno sociolingüístico en el cual una misma persona habla dos o más lenguas. También se define como la coexistencia pacífica o conflictiva de dos o más lenguas en un territorio. Weinreich (1974) especifica que dos o más lenguas están en contacto sin son usadas alternativamente por las mismas personas, y los individuos que usan las lenguas son, por tanto, el punto de contacto. Silva (1989) señala que dos o más lenguas entran en contacto cuando son usadas por los mismos individuos, es decir, cuando existe una situación de bilingüismo (o multilingüismo) en la que los hablantes bilingües constituyen el locus de contacto. Ramírez (1996) ratifica la idea anterior, el contacto de lenguas da lugar a las siguientes situaciones: bilingüismo, lenguas de relación y lenguas criollas.

Coseriu (1973) afirma que la lengua cambia justamente porque no está hecha, sino que se hace continuamente por la actividad lingüística. En otros términos, «cambia porque se habla [...]. La lengua, pues, no se impone al hablante, sino que se le ofrece: el hablante dispone de ella para realizar su libertad expresiva». Por su parte, Malmberg (1971), señala que volvemos de nuevo a la interdependencia entre lenguaje y sociedad y a la conclusión de que el cambio lingüístico, apurando la definición, no es un fenómeno lingüístico, sino social.

En efecto, el cambio lingüístico es un fenómeno social, porque las lenguas se materializan o ejecutan en la sociedad, específicamente, en la interacción social de los hablantes. Sapir (1971) explica que el lenguaje avanza a lo largo del tiempo, a través de una corriente que él mismo se crea: Fluye y se transforma sin cesar [...]. Ahora bien, los dialectos no surgen del simple hecho de la variación individual, sino de la circunstancia de que dos o más grupos de individuos se han separado lo suficiente para avanzar cada uno por su lado, independientemente, en lugar de ir juntos.

Por su lado, Lavov (1996) estableció tres factores sociales que influyen en el cambio lingüístico y en el mecanismo de los préstamos. 
Estos son los siguientes:

a) el principio del mínimo esfuerzo;

b) el principio de la densidad;

c) el principio de la imitación;

d) las clases de cambios lingüísticos.

Sobre las causas del contacto lingüístico, Limo y Salcedo (2006) explican que el contacto lingüístico grupal se da a partir de desplazamientos de población. Según ellas, estas movidas sociales o desplazamientos están suscitados por las conquistas, las migraciones, las comunicaciones globales y el turismo. A estos factores añadimos otros dos que son el comercio y el trabajo. Como indican Limo y Salcedo, el contacto lingüístico siempre va a derivar en la necesidad de aprender parte de la lengua del otro. Por lo tanto, se podría afirmar que el bilingüismo es la consecuencia esperable y natural del contacto prolongado entre las lenguas. Asimismo, las invasiones, el contacto mercantil, los viajes de descubrimiento o la expansión imperial dejan su impronta en la lengua o, mejor, la lengua se adapta a las nuevas tensiones (Tejada, 1999).

\subsection{Préstamo lingüístico}

El préstamo es un fenómeno sociolingüístico en el cual los hablantes de una lengua utilizan palabras de otra lengua. Durante ese proceso de transferencia, la palabra prestada sufre un proceso de adaptación fonética, morfológica y sintáctica. Al respecto, Crystal (2000) define al préstamo como una unidad lingüística (habitualmente un ítem léxico) que se usa en una lengua o dialecto distinto de aquel en el que se originó. Hjemslev, citado por Lewandowski, señala que el préstamo es una transferencia de un signo de una lengua a otra, en la que se conserva en general las funciones de los elementos y se da el enriquecimiento del repertorio o vocabulario de una lengua, de un dialecto o dialecto a base del dialecto de otra lengua, de otro dialecto o idiolecto (Lewandowski, 1982). El préstamo, asimismo, es «el elemento lingüístico (léxico, de ordinario) que una lengua toma de otra, bien adaptándolo en su forma primitiva, bien imitándolo y transformándolo más o menos» (Carreter, 1971). También, 
es un término curioso, porque las lenguas nunca devuelven lo que toman prestado (Bernárdez, 2012), por lo que conviene usar el vocablo adopción o adaptación de una forma extranjera. El préstamo, además, es el elemento de una lengua que, mediante un proceso de adaptación fonológica y morfológica se integra a otra lengua. También, se le denomina extranjerismo, neologismo o calco (Luna et al., 2005).

La primera valla a superar o la primera prueba de fuego que debe superar el extranjerismo es la adaptación y acomodo fonético. Pocas veces impone su pronunciación original, generalmente pierde y se somete a las reglas fonéticas de la lengua receptora (Deroy, 1956).

Por otro lado, entre las causas del préstamo lingüístico se encuentran las siguientes:

- Necesidad;

- Las lenguas son dinámicas en su naturaleza;

- La novedad, la moda y el prestigio del término prestado;

- La aparición de nuevos bienes o acciones;

- Como todo ser, las lenguas cambian con el tiempo.

Asimismo, entre las consecuencias del préstamo lingüístico se encuentran las siguientes:

- Con los préstamos, la lengua se mantiene viva y enriquecida en su léxico.

- Oposición y protesta infructuosa por parte de los defensores «puristas» de la lengua.

- Cambios o modificaciones en el sistema léxico de la lengua prestante.

Sobre el préstamo, desde el punto de vista cognitivo, Lakoff (1987) afirmó contundentemente que las categorías lingüísticas son tipos de las categorías cognitivas. Las categorías lingüísticas, así como las categorías conceptuales presentan efectos prototípicos. Dichos efectos se observan en el nivel del lenguaje, desde la fonología a la morfología, 
desde la sintaxis al léxico. Consideró la existencia de dichos efectos como la prueba de que las categorías lingüísticas tienen el mismo carácter que las categorías conceptuales.

En este sentido, los préstamos lingüísticos que corresponde al nivel léxico parten desde lo cognitivo. O sea, se suscitan en el cerebro del hablante, de tal manera que solo podría explicarse desde la Lingüística Cognitiva.

¿Qué sucede en la mente del hablante cuando va a adoptar o prestarse una palabra extranjera? ¿Qué sucede en la mente del quechuahablante cuando este por primera vez observa un objeto nuevo para él o ella, por ejemplo, un celular? Consciente o inconscientemente se interrogará qué cosa es esto y preguntará a alguien. Aunque la pregunta es por el objeto, la única respuesta posible será la palabra, exactamente el sustantivo o nombre de ese objeto. Si alguien ya sabe el nombre del objeto, le dirá: «este es celular». Hasta es probable que además le explique para qué sirve y cómo funciona. Él o ella repetirá mentalmente la palabra celular, y la pronunciará en una oración; así, este extranjerismo pasará a su repertorio léxico. Pero si no hubiese tenido a nadie que le diga el nombre de ese objeto, seguro se vería forzado a inventarle un nombre para ese ser. Para hacerlo, es decir, para darle nombre a ese nuevo ser, la única posibilidad es buscar en su mente el nombre de un objeto ya conocido por él que se le parezca al nuevo objeto celular. A dicha actividad mental en Lingüística cognitiva se denomina categorización, pues lo que ha hecho es buscar prototipos o estereotipos (familiaridad o semejanza entre el celular y el objeto conocido).

Pero supongamos que eso ocurre con cada quechuahablante. Entonces, cada hablante del quechua nombrará al celular según el prototipo que conoce, su imaginación y su capacidad denominativa. Y es imposible que cada individuo use el mismo prototipo. Esto generará un problema de pluridenominación que sobrepasaría los sinónimos y no lograrían entenderse. Kleiber (1995) explica el peligro de las denominaciones individuales a partir de los prototipos: el prototipo es el ejemplar que es reconocido como el más idóneo para los individuos. 
https://doi.org/10.46744/bapl.201902.004

Este fundamento psicológico plantea el problema de la variación individual, puesto que, al ser en primer lugar el mejor caso que a los individuos les viene a la mente, el prototipo podría, en teoría, variar de un individuo a otro.

Por su parte, los cronistas ilustran este caso cuando expresan por primera vez las percepciones sobre el caballo, un ser desconocido por los indígenas inicialmente. Ellos lo denominaban de las siguientes maneras: hatun alqu 'perro grande', k'ala llama 'llama pelada', ichina uywa 'animal para montar', qulqi muqbuy hatun uywa 'animal grande que come plata'. Veamos un texto ilustrativo de Cieza de León (1974):

Venían caballeros en unas llamas grandísimas que en su corrida y velocidad parecían guanacos, que traían unas pucunas o cerbatanas con que soplaban fuego, con más espantable ruido que el Inti Illapa, y que traían unas macanas o cuchillos tan largos como casi una braza, con que cortaban un hombre por medio.

Como se puede observar, los informantes del inca, para describir los nuevos seres, tales como caballos, escopetas y espadas, recurren al prototipo que ellos conocen:

Caballos = llamas grandísimas, parecido a los guanacos .

Escopetas $=$ phukunas que soplan fuego, con ruido como del Illapa ('relámpago').

Espadas = maqanas 'cuchillos' tan largos que cortan al hombre por medio.

Las denominaciones habrán sido muchas y variadas. Pero ¿por qué hoy en día el quechuahablante ya no nombra llama grande o guanaco al caballo, ni phukuna que sopla fuego al relámpago? La respuesta radica en la semántica de los prototipos, rama de la Lingüística Cognitiva. Veamos:

1) Porque, en estos casos, la mente del quechuahablante al realizar el proceso de categorización general pasa a la 
subcategorización (buscar prototipos más específicos). Y, al hacer ello, no puede completarlo tan bien, porque, además de que se trata de palabras referidas a animales rumiantes, mamíferos, de carga, no hay más equivalencias o prototipos entre caballo y llama, para nombrarlos de esa forma.

2) Porque cada quechuahablante ha nombrado como pudo según el prototipo familiar y de forma tan diversa.

3) Porque ese problema se resolvió al escuchar a los españoles (dueños de los caballos y las escopetas y espadas); es decir, decidieron llamarlo como los españoles. En otras palabras, según la semántica de los prototipos, optaron por el que «resulta ser cognitivamente el más idóneo». De acuerdo con Kleiber (1995), caballo, escopeta y espada serían términos del nivel de base, «nivel en el que se efectúa la denominación estándar» (según todos españoles). Entonces, los quechuahablantes acudieron al préstamo y con eso redenominaron a los nuevos seres de manera estandarizada e incorporaron a su repertorio léxico nuevas palabras adaptándolas, por su puesto, a la fonología quechua.

Otro caso ilustrativo es lo que refiere Domingo de Santo Tomás (1995): las cosas de nuestra fe explícanse o por los propios términos como está dicho o por circunloquios, o por los nombres de las causas o efectos de las cosas que se quieren explicar o declarar (Foja 42v).

En la cita, se explica un conflicto lingüístico-cognitivo. En los primeros años de contacto con los españoles, los quechuahablantes, al encontrarse con nuevos conceptos referidos a la religiosidad cristiana - para entender y expresarse en quechua- buscan equivalentes o prototipos, en muchos casos lo realizan a través de circunloquios (rodeo de palabras). Basándose en las causas y los efectos de lo que quieren decir, crean o inventan lexías o palabras equivalentes. Pero que, a la larga, no hallan consenso entre ellos mismos. La única salida es prestarse del castellano.

Por lo explicado, la invención de equivalencias en quechua para ciertos seres, acciones, procesos y objetos venidos de otras culturas 
y sociedades, que hacen los promotores de la Academia Mayor de la Lengua Quechua, nunca será acogida en la cognición ni en el lexicón de los quechuahablantes, que son una inmensa mayoría mucho más que los de la Academia. Y la única y la más efectiva forma de acrecentar el repertorio léxico del quechua - convertirla en una lengua del siglo xxIes la adopción y adaptación de los extranjerismos.

\subsubsection{Formas y clases del préstamo lingüístico}

a) Directos si es que una lengua $\mathrm{A}$ presta directamente a una lengua $\mathrm{B}$.

b) Indirectos si es que una lengua $\mathrm{A}$ presta vocablos a una lengua $\mathrm{B}$ por intermedio de una lengua $\mathrm{C}$.

Prat (1980) propuso los términos étimo inmediato o directo y étimo último o indirecto para clasificar a los préstamos al tener en cuenta su recorrido histórico. Así, según Prat (1980), el «étimo último» es el préstamo del préstamo. Es decir, es la palabra que una lengua $C$ se presta de la lengua $\mathrm{B}$, pero que a su vez esta lengua $\mathrm{B}$ se prestó de otra lengua, que es la A, como sucedió en el caso de «té», que el castellano la tomó del inglés, pero el inglés a su vez tomó del chino. En contraste, el «étimo inmediato» es aquel vocablo que una lengua B tomó directamente de la lengua $\mathrm{A}$, y esta lengua de ninguna otra.

Según Gómez (1998), la adopción de las palabras procede en un proceso tripartito que constituye las escalas de integración lingüística de los préstamos:

a) Transferencia. Es el mismo momento de la transferencia de la palabra de una lengua a la otra. Es decir, el acto en el cual un hablante o hablantes emplean una palabra extranjera.

b) Adaptación. Etapa en la que la palabra extranjera sufre un proceso de adaptación, variación y acomodación fónica, morfológica, semántica y hasta gráfica, según los rasgos propios de la lengua que la acoge. 
https://doi.org/10.46744/bapl.201902.004

c) Nativización. Fase en la cual la palabra ya está debidamente adaptada y considerada nativa. Esta aporta de manera positiva a la actualización y dinamización de la lengua receptora.

\subsection{El quechua: datos generales}

Los primordiales rasgos fonético-fonológicos del quechua son los siguientes:

a) Es una lengua trivocálica. Alencastre (1953), en su tesis, concluyó que «1. El quechua solo posee tres fonemas vocales. 2. Los tres fonemas vocales del quechua deben de ser graficados solamente con las letras $a, i, u$, para simplificar la escritura». Y, el año 2003 se afirma que «[...] el vocalismo del quechua está formado por un sistema triangular mínimo consistente de dos vocales altas /i, u/ y una baja /a/» (Cerrón, 2003).

b) Es una lengua de acento fijo. La mayor fuerza de voz de las palabras quechuas recae en la penúltima sílaba. Es decir, las palabras quechuas, por su acento, son graves.

c) Es una lengua carente de grupos vocálicos. El quechua carece de diptongos e hiatos. Como muestra tenemos ayni, quyki, paymi, chawpi, rawrak, tawna, qheswa, lliwllita.

d) Es una lengua que se caracteriza por desconocer las consonantes $b, d, g, f, j$ (tres oclusivas y dos fricativas).

e) Es una lengua carente de consonantes tautosilábicas. No presentan la combinación de fonemas licuantes y líquidos, tales como $b r, b l, t r, d r, p l, f r$, etc.

f) Su sílaba puede terminar en vocal o consonante. Ej.: ri y man.

g) Sus sílabas, generalmente, tienen la estructura siguiente: V, CV, VC, CVC y CVCC. Ej.:

$-\quad \mathrm{V} \rightarrow \mathrm{A}$

- $\quad \mathrm{CV} \rightarrow \mathrm{qu}$.

$-\quad \mathrm{VC} \rightarrow \mathrm{In}$ 
https://doi.org/10.46744/bapl.201902.004

- $\quad$ CVC $\rightarrow$ kil.

- CVCC $\rightarrow$ Qiwq - qi. (Según Antonio Cusihuamán, se refiere a la putrefacción que afecta a la papa, lisa u olluco.)

De manera particular, el quechua cusco-qollao presenta tres características privativas:

- Cuenta con palabras de pronunciación glotalizada como t’ika, t'uru, ch'uspa, k'anka.

- Tiene palabras de pronunciación aspirada como khasay, thuqay, thasnuy.

- Presenta evidentes alofonías como en [UrqU] y en [IrqI] (pronúnciese la $U$ y la $I$ más abiertas y más alargadas, casi como $o$ y $e$ ).

En junio del año 2014, previo a un acuerdo entre todas las instituciones y personalidades involucradas con el idioma quechua, el Ministerio de Educación estableció definitivamente el siguiente alfabeto para el quechua sureño: $a, c h, c h b, c b^{\prime}, h, i, k, k h, k^{\prime}, l, l l, m, n, \tilde{n}, p, p h, p^{\prime}$, $q, q h, q^{\prime}, r, s, t, t h, t^{\prime}, u, w, y$.

Como podemos ver, el quechua consta de un total de 28 fonemas segmentales lineales: 25 consonantes y 3 vocales $/ \mathrm{a} /, / \mathrm{I} / \mathrm{y} / \mathrm{U} /$.

Por su parte, los rasgos morfosintácticos del quechua son los siguientes:

a) Es una lengua aglutinante o sufijante. Se forman palabras añadiendo sufijos a la raíz de tal manera que se generan nuevas ideas o matices significativos. Ej:

Llaqta Pueblo

Llaqta $+-\mathrm{y} \_$Mi pueblo

Llaqta $+-\mathrm{y}+-\mathrm{mi} \quad$ Es mi pueblo

Llaqta $+-\mathrm{y}+-$ man A mi pueblo

Llaqta $+-\mathrm{y}+-$ man $+-\mathrm{mi}$ Es a mi pueblo 
https://doi.org/10.46744/bapl.201902.004

Llaqta $+-y+-$ man +- ta +- puni De mi pueblo mismo

Llaqta +- cha $+-y+-$ man +- ta + -puni De mi pueblito mismo

b) Carece de prefijos e infijos o interfijos. No cuenta con morfemas que se antepongan a la raíz, tampoco con morfemas que se interpongan entre la raíz y el sufijo solo para darle eufonía a la palabra. Calvo (1993) señala que «[...] la palabra quechua, ausente de todo tipo de prefijos, consta de una raíz pura (como muna 'querer') y una serie más o menos larga de sufijos (munasqa-yki-manta 'de lo que tú querías...')».

c) Es una lengua con sintaxis algo flexible; pero en la estructura oracional predomina la secuencia SOV: Sujeto, Objeto y Verbo. Ej.:

A.

$\frac{\text { Sujeto }}{\text { Kuraq wawayqa }} \frac{\text { Objeto }}{t^{\prime} \text { antatan }} \frac{\text { Verbo }}{\text { rantisqa. }}$

B.

$\frac{\text { Sujeto }}{\text { Mamayqa }} \frac{\text { Objeto }}{\text { punchukuna }} \frac{\text { Verbo }}{\text { awaytan yachan. }}$

d) Los adjetivos siempre anteceden al sustantivo; es decir, los modificadores siempre van antes del núcleo. Ej.:

$\frac{\text { Adj. }}{\text { Waq }} \frac{\text { Adj. }}{\text { ch'anchaku }^{\prime}} \frac{\text { Adj. }}{\text { suwa }} \frac{\text { Adj. }}{\text { ch'aku }^{\prime}} \frac{\text { Sust. }}{\text { alqucha }}$

e) El poseedor precede al poseído.

\section{$\frac{\text { Poseedor }}{\text { Maryanuk }} \frac{\text { oseido }}{\text { churin }}$}

f) La proposición subordinada antecede a la proposición principal. Ej.: 


\section{ORACIÓN}

$\frac{\text { Proposición Subordinada }}{\text { Chay kunbapatapi rantisqay yanaturutan suwarapuwanku. }}$

g) Los sufijos cumplen la función de los conectores (conjunciones y preposiciones). Calvo (1993), sobre los conectores, indica: «La particularidad de estos es que son internos a la lengua - pertenecen por tanto a la morfología flexiva - y no han llegado a independizarse como palabras» (p. 49).

$\frac{\text { Warmi }}{\text { Mujer }} \frac{n}{\frac{S u}{\text { RAIZ }}} \frac{\text { wan }}{\text { SUn }} \frac{\text { Anta }}{\text { SUF. }} \quad \frac{\text { kama }}{\text { Anta }} \frac{\text { Hasta }}{\text { SUF. }}$

h) Carece del artículo. El quechua es una lengua que no necesita del artículo.

La mayoría de los sustantivos, por su género son heterónimos y de forma fija.

i) Los sustantivos colectivos se forman por duplicación de las raíces.

j) Consta de solo seis categorías gramaticales.

\section{Metodología}

Esta investigación corresponde al paradigma cuantitativo, porque se cuantifican los resultados, principalmente, en el hecho de registrar la cantidad de los valores, según los criterios. Para la elaboración del corpus, se seleccionaron conversaciones con 49 quechuahablantes monolingües analfabetos de las 8 comunidades y sectores del distrito de Paccarectambo, provincia de Paruro, departamento de Cusco. Se realizó una grabación en una misa íntegramente en quechua celebrada un domingo por el sacerdote de Paccarectambo. Dichas conversaciones espontáneas y la misma misa fueron registradas con una grabadora profesional o con una grabadora de audio de un celular. Luego, esos discursos fueron transcritos a una computadora. Al finalizar, se seleccionaron 50 textos. Para la determinación, análisis y clasificación de los préstamos, se tomaron en cuenta los siguientes cinco criterios: 1) la categoría gramatical a la cual 
pertenecen los préstamos, 2) la procedencia originaria, 3) el étimo, 4) la nativización, 5) las equivalencias o no en el quechua. En la descripción y explicación de los préstamos, se consideran los procedimientos de adaptación morfofonológica que sufrieron los préstamos para ser adoptados por el quechuahablante.

Respecto de la población, según datos del INEI (Instituto Nacional de Estadística e Informática), Paccarectambo tiene una población de 2440 habitantes. Empero, la población de nuestra investigación únicamente la constituyen 64 ancianos. La muestra para este estudio ha sido tomada de manera no aleatoria por la naturaleza de los objetivos que se persigue. La muestra la constituyen personas de 60 años a más, hombres y mujeres, analfabetos, monolingües o bilingües incipientes.

\section{Resultados y discusión de los resultados}

El préstamo lingüístico, en su mayoría, siempre afecta al sistema morfofonológico. Los préstamos identificados y analizados en los 50 textos del CORQUERUPA (Corpus del Quechua Rural de Paccarectambo), presentan los siguientes rasgos. A las vocales $E$ y $O$ que contenían palabras castellanas, el quechuahablante las adaptó a $I$ y $U$. Como muestra tenemos: infirmirakuna 'enfermeras', tumarisqa 'tomado', kariñusu 'cariñoso', rispitusu 'respetuoso', etc. Los vocablos castellanos con diptongo e hiato como viaje y ríos fueron adaptados a biyahisun y riyus. Esto porque el quechua es una lengua carente de diptongos e hiatos. Las palabras agudas, esdrújulas o sobresdrújulas del castellano perdieron dicha condición para someterse a la acentuación quechua fija que únicamente acepta palabras graves o paroxítonas, como en carnaval [karnáwal], color [kúlur]. En algunos casos de préstamos con grupos consonánticos, se han conservado, como en kubraqtaq, kriyiniñachu, trawmasqa. En otro, se produjo una traslocación o cambio de posición del fonema /r/, como en purblimatica de problemática, intirgapuni de entregar. En algunos casos, los fonemas /f/, /b/, /d/, /g/ de las palabras castellanas, al quechuizarse, han sido adaptados como sucede en los siguientes casos: de selva a silwapi, de lavadero a lawadiru, de caballo a 
kawallu. En otros fueron adoptados por los quechuahablantes, como en biyulintu, bawtisakuychis, pagutapas, gamunal. En el campo propiamente morfológico, el procedimiento de adaptación más usual al que recurrió el quechuahablante al momento de quechuizar palabras castellanas fue la sufijación, como en fistakunapi, suldadukunawan, jubinlla, chikallaraq. Y, en pocos casos, la yuxtaposición y composición.

Tabla 1. Total de palabras de los 50 textos del CORQUERUPA

\begin{tabular}{|l|c|c|}
\hline Total de palabras quechua & 6011 & $86 \%$ \\
\hline Total de préstamos & 969 & $14 \%$ \\
\hline Total de palabras en los 50 textos & 6980 & $100 \%$ \\
\hline
\end{tabular}

De las 6980 palabras utilizadas en los 50 textos y que constituyen el CORQUERUPA, como puede observarse, los préstamos solo constituyen el $14 \%$ del total. Esto indica que, a pesar de que todos los textos transcritos exhiben préstamos, estos existen en su minoría y no representan una verdadera amenaza contra el sistema lingüístico que es el quechua. Esto es entendible, por cuanto el sistema lingüístico tiene 5 niveles: léxico, semántico, fonológico, morfológico y sintáctico. Los préstamos analizados corresponden solo a un nivel: el léxico. Y, por lo tanto, no pueden cambiar a la lengua como sistema, más al contrario, los préstamos se someten al sistema.

Carreter (2003) asevera que "cientos de neologismos entran en nuestra lengua con su pan bajo del brazo; quiero decir, con las cosas nuevas que nombran o con matices que no percibíamos; salud para ellos y bienvenidos sean, pues traen modernidad y ganancia». Como se puede notar, Lázaro Carreter toma a los préstamos de manera positiva para la lengua castellana. $\mathrm{Y}$, es así como se debe considerar los préstamos que ingresan como neologismos en el quechua, pues incrementan el repertorio léxico de la lengua receptora. No son, pues, una amenaza, porque la palabra que se presta es siempre objeto de una adaptación morfofonológica, pocas veces ingresa sin ninguna adaptación o tal como es. 
Tabla 2. Préstamos por la categoría gramatical

\begin{tabular}{|l|c|c|}
\hline \multicolumn{1}{|c|}{ Categoría gramatical } & Cantidad & $\%$ \\
\hline Sustantivo & 584 & $60,27 \%$ \\
\hline Verbo & 225 & $23,22 \%$ \\
\hline Adjetivo & 100 & $10,32 \%$ \\
\hline Adverbio & 34 & $3,51 \%$ \\
\hline Conjunción & 17 & $1,75 \%$ \\
\hline Interjección & 4 & $0,41 \%$ \\
\hline Acrónimo & 4 & $0,41 \%$ \\
\hline Preposición & 1 & $0,10 \%$ \\
\hline Total & 969 & $100 \%$ \\
\hline
\end{tabular}

En la tabla se muestran que los sustantivos son las palabras más prestadas. Los ejemplos son los siguientes : siñur 'señor', Hugo, makhiya 'magia', inkbiñiru 'ingeniero', prusur 'profesor', iskuyla 'escuela', kuñaru 'cuñado', gashusa 'gaseosa', papilcha 'papelito', kulur 'color', adubi 'adobe', llawi 'llave', bula 'bola, pelota', riwniyun 'reunión', trigu 'trigo', asukar 'azucar', akbus 'ajo', larankha 'naranja', turu 'toro', kawallu 'caballo', asuyla 'azuela', wiyudan 'viuda', etc. De esto se infiere que dos son las causas para ello: 1) como los sustantivos son los nombres de los seres, estos sustantivos ingresaron al quechua junto con sus referentes (personas, animales o cosas) procedentes de otras culturas; 2) los sustantivos, al igual que los verbos, las interjecciones, los adjetivos, los adverbios y las conjunciones son, lexicológicamente, de inventario abierto. El quechua es una lengua carente de acrónimos; sin embargo, con los préstamos que hace del castellano adopta y adapta esos acrónimos.

Se muestra también que la segunda categoría gramatical que más se presta es el verbo. Esto es porque con la aparición de nuevos seres parecen también sus nuevas acciones. Tanto los seres como sus acciones se incorporan a la cultura y a la lengua quechua. Asimismo, se muestra en el cuadro que las categorías que nunca se ha prestado el quechua son 
https://doi.org/10.46744/bapl.201902.004

el artículo y el pronombre; el artículo porque el quechua no tiene y no requiere artículos. El pronombre porque este es de inventario cerrado en el quechua, como en todas las lenguas, y no admite más palabras incluso en el quechua mismo. Lo extraño es la presencia extraña de la preposición hasta. Como se sabe, el quechua carece de esta categoría gramatical, y en su reemplazo, más bien, tiene sufijos con función de preposiciones. Viendo desde el punto de vista de su nativización, aún no es una palabra nativizada.

Estos resultados coinciden con los anteriores realizados por Whitney (1981). Él, en sus estudios sobre los préstamos, estableció la siguiente jerarquía de los préstamos:

\section{SUSTANTIVO > OTRAS PARTES DE LA ORACIÓN > SUFIJO > INFLEXIÓN > SONIDOS}

Como se observa, similar a nuestros resultados, la categoría que más se prestan los hablantes es el sustantivo. La diferencia entre los resultados de Whitney y los nuestros es que el primero no precisa qué categoría gramatical le sigue al sustantivo. Asimismo, afirma que también se prestan los sufijos, la inflexión y los sonidos. En cambio, en nuestro caso, no hemos encontrado préstamos en el quechua a nivel de los sufijos y la inflexión, solo a nivel de los sonidos, como la mayoría de los fonemas oclusivos. Unos años después, Haugen (1950) y Singh (1982) establecieron el siguiente orden:

\section{SUSTANTIVO > VERBO > ADJETIVOS > ADVERBIOS $>$ PREPOSICIONES > INTERJECCIONES}

Esta jerarquía nos parece más cercana a la nuestra con la diferencia de que el quechua carece de preposiciones. Por otro lado, en los textos 7, 23, 42 del CORQUERUPA se observan vocablos como sinukis (si no que, conjunción adversativa); utaq (o, conjunciones disyuntivas); sichus (si, conjunción condicional). Como demuestra la tabla, los préstamos del castellano al quechua son incluso a nivel de las conjunciones. 
Niel Palomino Gonzales

https://doi.org/10.46744/bapl.201902.004

Tabla 3. Préstamos por la procedencia

\begin{tabular}{|c|c|c|}
\hline Procedencia & Cantidad & $\%$ \\
\hline latino & 792 & $81,73 \%$ \\
\hline helenismo & 34 & $3,51 \%$ \\
\hline germano & 27 & $2,79 \%$ \\
\hline galicismo & 27 & $2,79 \%$ \\
\hline arabismo & 19 & $1,96 \%$ \\
\hline hebreísmo & 11 & $1,14 \%$ \\
\hline anglosajón & 8 & $0,83 \%$ \\
\hline hispanismo & 7 & $0,72 \%$ \\
\hline italiano & 7 & $0,72 \%$ \\
\hline catalán & 5 & $0,52 \%$ \\
\hline provenzal & 4 & $0,41 \%$ \\
\hline gallego & 3 & $0,31 \%$ \\
\hline sánscrito & 3 & $0,31 \%$ \\
\hline vasco & 3 & $0,31 \%$ \\
\hline gótico & 2 & $0,21 \%$ \\
\hline incierto & 2 & $0,21 \%$ \\
\hline caribeño & 2 & $0,21 \%$ \\
\hline egipcio & 2 & $0,21 \%$ \\
\hline indoeuropeo & 2 & $0,21 \%$ \\
\hline mapuche & 2 & $0,21 \%$ \\
\hline mandingo & 1 & $0,1 \%$ \\
\hline celta & 1 & $0,1 \%$ \\
\hline checo & 1 & $0,1 \%$ \\
\hline fenicio & 1 & $0,1 \%$ \\
\hline chino & 1 & $0,1 \%$ \\
\hline portugués & 1 & $0,1 \%$ \\
\hline
\end{tabular}


https://doi.org/10.46744/bapl.201902.004

\begin{tabular}{|l|c|c|}
\hline neerlandés & 1 & $0,1 \%$ \\
\hline Total & 969 & $100 \%$ \\
\hline
\end{tabular}

La tabla nos muestra en primer término que solo siete palabras de las 969 son de origen «netamente» españolas. Las siete voces constituyen apenas el 0,72\% del total. En cambio, un 81,73\% de los préstamos lo constituyen vocablos latinos, seguida de 25 lenguas. Así, tenemos por ejemplo en el texto 33 del CORQUERUPA expresiones del quechuahablante como santatirra 'santa tierra', kurpuchanta 'a su cuerpito', urushunta 'la oración', almachapas 'el almita también', buynullan 'bueno no más', mintasqa 'mentado', tardiña 'ya es tarde', etc. todos de origen, latino.

Los resultados confirman lo ya sabido, esto es, que la mayor base léxica del español es el latín. Asimismo, los resultados nos recuerdan las afirmaciones de la Dra. Eliana Gonzales Cruz (2009). Ella dice sobre el castellano que «[...] es una de las varias lenguas romances, románicas o neolatinas surgidas del latín, lengua hablada por los antiguos romanos». Esta mayor cantidad de palabras latinas se explica porque el castellano es una lengua romance, llamado también neolatino. De la explicación de la presencia de las 23 lenguas y de una incierta, se infiere que una lengua, lexicológicamente, no nace, crece, se consolida ni muere con sus propias palabras, sino, prestándose términos de otras lenguas. Y, en ese proceso dinámico de adopción y adaptación, los neologismos se nativizan. Así, todas las palabras castellanas, pese a su procedencia de otras lenguas, sincrónicamente son españolas.

Tabla 4. Préstamos por el étimo

\begin{tabular}{|l|c|c|}
\hline \multicolumn{1}{|c|}{ Étimo } & Cantidad & $\%$ \\
\hline Indirecto & 962 & $99 \%$ \\
\hline Directo & 7 & $1 \%$ \\
\hline Total & 969 & $100 \%$ \\
\hline
\end{tabular}


La tabla nos muestra que $99 \%$ de los préstamos son indirectos y solo $1 \%$ es directo. El porcentaje superior de préstamos indirectos significa que la mayor cantidad de palabras que el quechua se ha prestado, no son netamente castellanas, si no que el castellano también se ha prestado de otras lenguas. Luego, las ha castellanizado o nativizado, y esos vocablos ya han pasado al quechua. Así, en la expresión Pulisiyamañ̃a = 'Ya al policía', registrada en el texto 30 del COQUERUPA, haciendo el análisis etimológico, se tiene que policía deriva del griego politeía, pasó al latín politīa, de ahí al español policía, y, finalmente, al quechua como pulisiya. El caso del término alkilirlla del texto 34 del CORQUERUPA, se tiene que proviene del árabe aljirā, de ahí pasó al español y del español al quechua. En el texto 12 del CORQUERUPA, se registra el vocablo parlakusaq = 'hablaré'. Como sabemos, la palabra latina parla no se emplea en castellano, pero en el quechua sí y de manera muy frecuente. El préstamo se dio directamente del latín al quechua, sin la filtración castellana. Al respecto, Prat (1980) sostiene que los préstamos son étimos. Estos pueden ser primeros o últimos, generalmente, directos, como los que encontramos, porque la lengua $\mathrm{C}$ se presta directamente de la lengua B. En contraste, los étimos indirectos son aquellos que una lengua $C$ se prestó de la lengua $\mathrm{B}$, pero que, a su vez, esta lengua $\mathrm{B}$ se prestó de la A.

Tabla 5. Préstamos según la nativización

\begin{tabular}{|l|c|c|}
\hline \multicolumn{1}{|c|}{ Nativización } & Cantidad & $\%$ \\
\hline Nativizado & 763 & $78,74 \%$ \\
\hline No nativizado & 115 & $11,87 \%$ \\
\hline En proceso & 91 & $9,39 \%$ \\
\hline Total & 969 & $100 \%$ \\
\hline
\end{tabular}

La tabla muestra que el 78,74 \% de las palabras prestadas son nativizadas; $11,87 \%$ no nativizados, y el 9,39\% en proceso. La nativización implica que el vocablo prestado, después de los procesos de adaptación morfofonológicas, se incorpore en la lengua como una palabra 
nativa. Esos préstamos se han integrado al quechua completamente y su uso se ha extendido en la totalidad de hablantes, a tal punto que esas palabras prestadas ya parecen originarias quechuas como ocurre con la voz chanza, adubi, martis, akbus, arrus, asukar, laranja, kawallu, trigu, karnawal, pagawan, prusur, rispitu, etc. todos regsitrados en los diversos textos transcritos quecontiene el CORQUERUPA. Las que están en proceso de nativización, y las que aún no, de manera inexorable, pronto serán palabras nativas y, en la dinamicidad de la lengua, aparecerán nuevos préstamos que se nativizarán.

Los datos expuestos en los resultados coinciden con lo explicado por los sociolingüistas Hope y Gómez Capuz (1971, 1998). Según ellos, los préstamos lingüísticos hasta su nativización en la lengua receptora atraviesan las etapas de transferencia y adaptación para finalmente quedarse con la etapa llamada nativización. El vocablo nativizado llega a constituirse como tal, cuando ha sido adaptado por completo y su uso se extiende por el tiempo y el espacio.

Según la nativización, la mayoría de los préstamos ya se han quechuizado o nativizado, algunos están en proceso, y los no nativizados entrarán al proceso de nativización.

Tabla 6. Préstamos por la equivalencia en quechua

\begin{tabular}{|l|c|c|}
\hline \multicolumn{1}{|c|}{ Equivalencia } & Cantidad & $\%$ \\
\hline Con Equivalencia & 487 & $50,26 \%$ \\
\hline Sin Equivalencia & 482 & $49,74 \%$ \\
\hline Total & 969 & $100 \%$ \\
\hline
\end{tabular}

La tabla muestra que entre préstamos con equivalencia y préstamos sin equivalencia hay una mínima diferencia de apenas 0,54 $\%$ equivalente a 5 palabras. De esos 5 vocablos a favor de los préstamos sin equivalencia, se infiere que el préstamo hacia el quechua se da porque el quechuahablante no halla equivalentes del castellano y opta por el 
préstamo. Esta idea coincide con la de Edward Sapir (1971). Según él, «las lenguas, como las culturas, rara vez se bastan a sí mismas. Las necesidades del intercambio establecen un contacto directo o indirecto entre los individuos que hablan una lengua y los que hablan lenguas geográficamente vecinas o culturalmente dominantes. El intercambio puede ser amistoso u hostil».

Así, por ejemplo, en el texto 1 del CORQUERUPA, se tiene vocablos como cuaderno [kuwarduta]; almanaque [almanakitapas]; naranja [laranqhata]. Estos vocablos carecen de equivalentes en quechua, y los quechuahablantes optaron por adoptarlos y adaptarlos. Por su parte, en el texto 4 del CORQUERUPA se identifica términos como antes [antista]; tomar [tumanaykupaqpas]; más [mastapascha]; de repente [riripintillamanta]. Empero, estos vocablos sí tienen equivalencias en quechua: antista = ñwpata; tomanaykupaqpas = upyanaykupaqpas; mastapascha $=$ aswantapascha; riripintillamanta $=$ yanqallamanta. Lo interesante es que estos préstamos con equivalencia no significan necesariamente exterminio del vocablo quechua, sino ingresan como sinónimos del vocablo quechua.

\section{Conclusiones}

Fonológicamente, las vocales /e/ - /o/ de las palabras castellanas, al momento de prestarse, son adaptadas por el quechuahablante a /i/ y /u/. Los vocablos castellanos con diptongo e hiato como viaje y ríos fueron adaptados a biyabisun y riyus. Las palabras agudas, esdrújulas o sobresdrújulas del castellano perdieron dicha condición para someterse a la acentuación quechua fija, que únicamente acepta palabras graves o paroxítonas. En algunos casos, los fonemas /f/, /b/, /d/, /g/ de las palabras castellanas al quechuizarse han sido adaptados y, en otros, fueron adoptados por los quechuahablantes.

En el campo propiamente morfológico, el procedimiento de adaptación más usual al que recurrió el quechuahablante al momento de quechuizar palabras castellanas fue la sufijación y, en pocos casos, la yuxtaposición y composición. 
https://doi.org/10.46744/bapl.201902.004

Con referencia a la categoría gramatical, el orden cuantitativo de los préstamos es el siguiente: Sustantivos $>$ Verbos $>$ Adjetivos $>$ Adverbios $>$ Conjunciones $>$ Interjecciones $>$ Acrónimos $>$ Preposiciones. Según la procedencia, diacrónicamente, el orden de los préstamos empieza con la procedencia latina y termina en neerlandés de un total de 27 lenguas que fueron objeto de préstamos al quechua. Según el étimo, los préstamos al castellano son indirectos, en primer orden, y directos, en segundo orden. Es decir, diacrónicamente, el castellano se prestó primero de las lenguas euroasiáticas y, luego, dichos préstamos ya castellanizados pasaron al quechua. Según la nativización, la mayoría de los préstamos ya se han quechuizado o nativizado, algunos están en proceso, y los no nativizados entrarán al proceso de nativización. Según la equivalencia, en el quechua, el $50,26 \%$ de los préstamos tienen equivalencia en el quechua, y el $49,74 \%$ de los préstamos no tienen equivalencia en quechua o sus equivalencias en los diccionarios quechuas son arcaicas o forzadas. Los préstamos o adopciones lingüísticas enriquecen, revitalizan, modernizan y mantienen vivo al quechua. 
https://doi.org/10.46744/bapl.201902.004

\section{BIBLIOGRAFÍA}

ALENCASTRE, Andrés, Kilku Warak'a (1953). Fonética, semántica y sintaxis quechua. Tesis para optar al grado de magíster en la Universidad Nacional de San Antonio Abad del Cusco.

BERNÁRDEZ, E. (1978). «Metodología para el estudio y la clasificación de los préstamos lingüísticos». Revista Española de Antropología Americana, XXXII, 235-256.

BLOOMFIELD, L. (1964). Lenguaje. Lima: Departamento de Publicaciones de la Universidad Nacional Mayor de San Marcos.

BOLAÑO, S. (1982). Introducción a la teoría y práctica de la sociolingüística. México: Trillas.

CALVO, J. (1993). Pragmática y gramática del quechua cuzqueño. Cuzco: Centro de Estudios Regionales Andinos Bartolomé de las Casas.

CASTILlO, N. (2002). «El préstamo léxico y su adaptación: un problema lingüístico y cultural». Revista OMAZEIN, IV, Número 7, 89-125.

CERRÓN-PALOMINO, R. (2003). Lingüistica quechua. Cuzco: Centro de Estudios Regionales Andinos Bartolomé de las Casas.

CIEZA DE LEÓN, P. (1973). Crónica del Perú. Madrid: Gredos.

COSERIU, E. (1973). Teoría del lenguaje y lingüística general. Madrid: Edit. Gredos S. A.

CRYSTAL, D. (2005). La revolución del lenguaje. Madrid: Alianza Editorial. . (2000). Diccionario de Lingüística y Fonética. Barcelona: Octaedro. 
https://doi.org/10.46744/bapl.201902.004

CUSIHUAMÁN, A. (1976). Gramática quechua: Cuzco-Collao. Lima: Instituto de Estudios Peruanos.

DEROY, L. (1956). L'emprunt linguistique. París: Les Belles Lettres.

FISHMAN, J. (1979). Sociología del lenguaje. Madrid: Cátedra.

GÓMEZ CAPUZ, J. (1998). El préstamo lingüístico. Conceptos, problemas y métodos. Valencia: Cuadernos de Filología.

HAUGEN, E. (1950). «The Analysis of Linguistic Borrowing». Revista Language, 26-2, 210-231.

HOCKET, Ch. F. (1972). Curso de Lingüística Moderna. Buenos Aires: Eudeba (Editorial Universitaria de Buenos Aires).

HOPE, T. E. (1971). Lexical Borrowing in the Romance Languages. Nueva York: New York University Press.

KLEIBER, G. (1995). La semántica de los prototipos, Categoría y sentido léxico. Madrid: Visor Libros.

LABOV, W. (1996). Principles of linguistic change. Internal factors (Principios del cambio lingüístico. Factores internos). Madrid: Gredos.

LAKOFF, G. (1987). Women, Fire and Dangerous Thinks. What Categories reveal about the Mind. Chicago and London. The University of Chicago Press.

LÁZARO, F. (1971). Diccionario de términos filológicos. Madrid: Gredos S. A. . (2003). El nuevo dardo en la palabra. Madrid: Planeta.

LEWANDOWSKI, T. (1982). Diccionario de Lingüística. Madrid: Cátedra S. A. 
https://doi.org/10.46744/bapl.201902.004

LIMO, A. y SALCEDO, A. (2006). Contacto de lenguas: una aproximación al caso del Perú y del español andino. ¿Cambio o muerte de las lenguas? Lima: Fondo Editorial de la Universidad Peruana de Ciencias Aplicadas.

LUNA, E. et al. (2005). Diccionario Básico de Lingüística. México D. F.: Editorial de la Universidad Nacional Autónoma de México.

MALMBERG, B. (1975) Lingüística estructural y comunicación bumana. Madrid: Cincel.

PINO, E. (2009). Etimologías grecolatinas. Veracruz: Editado por Secretaria de Educación de Veracruz.

PRATT, Ch. (1980). El anglicismo en el español peninsular contemporáneo. Madrid: Gredos.

RAMÍREZ, L. H. (1996). Estructura y funcionamiento del lenguaje. Lima: Editorial de la Derrama Magisterial.

REGUERA, A. (2008). Metodología de la investigación lingüística. Buenos Aires: Brujas.

ROMAINE, S. (1996). El lenguaje en la sociedad. Una introducción a la Sociolingüística. Barcelona: Ariel.

SANTO TOMÁS, D. (1995). Gramática o arte de la lengua general de los indios de los reynos del Perú. Estudio, introducción y notas de Rodolfo Cerrón-Palomino. Cuzco: Centro de Estudios Regionales Bartolomé de las Casas.

SAPIR, E. (1971). El lenguaje, introducción al estudio del habla. México D. F.: Fondo de Cultura Económica.

TEJADA, P. (1999). El cambio lingüístico, claves para interpretar la lengua inglesa. Madrid: Alianza Editorial. 
Préstamos lingǘsticos en el Quechua actual de las comunidades del distrito de Paccarectambo https://doi.org/10.46744/bapl.201902.004

TORERO, A. (2011). Cuestiones de lingüística e historia andinas. Huacho: Gráfica imagen.

WHITNEY, W. D. (1857). Language and the Study of Language: Twelve Lectures on the Principles of Linguistic Science. New York: Scribner, Armstrong \& Com. 